\title{
A Nova Gestão Pública como indutora das atividades de Engenharia de Produção nos órgãos públicos
}

\author{
lgor Rosa Dias de Jesus ${ }^{\text {a* }}$, Helder Gomes Costa ${ }^{b}$ \\ a*igdias@uol.com.br, UFF/EMBRAPA, Brasil \\ bhelder.uff@gmail.com, UFF, Brasil
}

\begin{abstract}
Resumo
0 propósito deste trabalho é o de mostrar como a Nova Gestão Pública, ao incorporar ferramentas e pontos de vista oriundos da iniciativa privada, abre espaço para maior atuação dos engenheiros de produção no Estado. Na introdução é apresentada uma contextualização histórica da evolução da gestão pública, desde o modelo patrimonialista, passando pelo modelo burocrático e pelo gerencial, até a assunção da Nova Gestão Pública. É também apresentada uma contextualização histórica da própria Engenharia de Produção. A busca por interfaces entre esses dois campos do conhecimento se deu a partir de uma investigação teórica, na qual se procurou entender quais práticas de gestão estariam associadas, simultaneamente, a elementos da Engenharia de Produção e da Nova Gestão Pública. Os resultados dessa investigação nos mostram que essa interface atinge todos os elementos da Nova Gestão Pública e todas as subáreas da Engenharia de Produção.
\end{abstract}

Palavras-chave

Nova Gestão Pública. Engenharia de Produção. Reforma gerencial. Setor público. Governo.

\section{Introdução}

Fleury (2008, p. 1) define a Engenharia de Produção da seguinte maneira:

\begin{abstract}
A Engenharia de Produção trata do projeto, aperfeiçoamento e implantação de sistemas integrados de pessoas, materiais, informações, equipamentos e energia, para a produção de bens e serviços, de maneira econômica, respeitando os preceitos éticos e culturais. Tem como base os conhecimentos específicos e as habilidades associadas às ciências físicas, matemáticas e sociais, assim como aos princípios e métodos de análise da engenharia de projeto para especificar, predizer e avaliar os resultados obtidos por tais sistemas.
\end{abstract}

Naturalmente, pode-se perceber que dentro dessa abordagem cabem não apenas os setores produtivos tradicionais, mas também outras atividades como ONGs, redes de empresas, interfaces colaborativas, e também as entidades governamentais.

Por outro lado, o movimento da Nova Gestão Pública (NGP) se caracteriza como

\begin{abstract}
[...] um modelo emergente de modernização da administração pública mundial, caracterizado por um conjunto de princípios e práticas de gestão, oriundos de um movimento de governos de diversos países no sentido de desenvolver alternativas e soluções para os desafios aos quais eram e ainda são colocados (como escassez de recursos públicos, aumento da pressão da sociedade por qualidade e que idade na prestação de serviços etc.), e para os quais o modelo burocrático não se mostrou capaz de responder satisfatoriamente. (PACHECO, 2008, p. 27).
\end{abstract}

Existe uma área de interface bastante grande entre essas duas áreas aparentemente distintas, a Engenharia de Produção e a gestão pública e é no sentido de preencher tal lacuna e elucidar alguns desses pontos de intersecção que reside o interesse deste trabalho.

Dessa forma, o propósito deste trabalho é verificar como a Engenharia de Produção possui espaço para ter seus métodos e ferramentas utilizados nos órgãos públicos nos dias de hoje, principalmente nos aspectos 
ligados ao planejamento e gestão governamentais, em especial depois da recente disseminação dos princípios e da filosofia da Nova Gestão Pública.

\section{Revisão de literatura}

Esta seção apresenta a revisão da literatura que sustenta este trabalho, estando dividida em três partes: abordagem histórica da Engenharia de Produção; abordagem histórica da gestão pública; e a Nova Gestão Pública.

\subsection{Abordagem histórica da Engenharia de Produção no Brasil}

De acordo com Fleury (2008), a Engenharia de Produção surgiu com as ideias de Taylor e Henry Ford, que aplicaram os princípios da administração científica em uma indústria siderúrgica e numa montadora automotiva, respectivamente. A administração científica consistia em estabelecer uma abordagem eficiente e econômica para o uso dos recursos. A Engenharia de Produção surgiu, portanto, em um ambiente industrial. Borchardt et al. (2009) afirmam que com o passar do tempo a Engenharia de Produção evoluiu para uma visão ampla que leva em conta diferentes stakeholders associados aos processos decisórios e de sustentabilidade de uma organização. Elementos regulatórios, de gestão ambiental, de percepção de qualidade e alinhamento de cadeias produtivas são hoje integrados às decisões de engenharia do produto ou do processo produtivo.

Oliveira, Barbosa e Chrispim (2005) resgatam a história da Engenharia de Produção no Brasil. A Engenharia de Produção tem sua origem no país quando a Escola Politécnica aprovou os cursos de Engenharia de Produção e Complemento de Organização Industrial como disciplinas do curso de doutoramento em Engenharia existente na época. Visto que a nova área estava sendo bastante solicitada pelo mercado, em 1958 foi aprovada, em nível de graduação, a criação do curso de Engenharia de Produção como opção à Engenharia Mecânica.

Ressalte-se que até o início da década de 1970 não existiam cursos de graduação em Engenharia de Produção como modalidade. Os cursos criados até então eram de pós-graduação ou de graduação, tendo a Produção como habilitação de outra modalidade de Engenharia. Ao que tudo indica, os dois primeiros cursos de Engenharia de Produção surgiram efetivamente no início da década de 1970 na UFRJ e na USP - São Carlos (OLIVEIRA; BARBOSA; CHRISPIM, 2005).
A partir daí, houve um crescimento exponencial dos cursos de Engenharia de Produção no Brasil. De acordo com Borchardt et al. (2009), no final da década de 1970 começaram a surgir outros cursos de EP, além dos existentes na UFRJ e na USP. Em 1980 já existiam 18 cursos, e até 1997 criaram-se aproximadamente dois cursos a cada três anos no país. A partir de 1998 houve um crescimento vertiginoso do número de cursos, chegando a aproximadamente 200 cursos em 2005; a evolução da oferta de cursos no Brasil pode ser vista na Figura 1. Atualmente, de acordo com a ABEPRO (ASSOCIAÇÃO..., 2011), a oferta de cursos de Engenharia de Produção é de 358 cursos.

Naturalmente, com tamanha aceitação do mercado e o crescimento expressivo da quantidade de cursos ministrados, a fiscalização sobre as competências necessárias à formação do engenheiro de produção foi se tornando necessária. Surgiu como entidade representativa a Associação Brasileira de Engenharia de Produção (ABEPRO), que tratou de propor os conteúdos necessários à formação do engenheiro de produção no Brasil, bem como as áreas de atuação do engenheiro de produção.

No entanto, dado o dinamismo da carreira e as múltiplas possibilidades de atuação, tais competências e áreas de atuação vêm sendo modificadas ao longo do tempo e hoje contam com uma ampla gama de atuação, que vão desde a área de mais quantitativas como operações e pesquisa operacional até áreas mais qualitativas como qualidade e sustentabilidade. A última versão das áreas de atuação definidas pela ABEPRO para a atuação do engenheiro de produção é do ano de 2008; e estas são definidas no Quadro 1.

\subsection{Abordagem histórica da gestão pública}

Bresser-Pereira (2005) estrutura a evolução da administração pública em três grandes fases, que

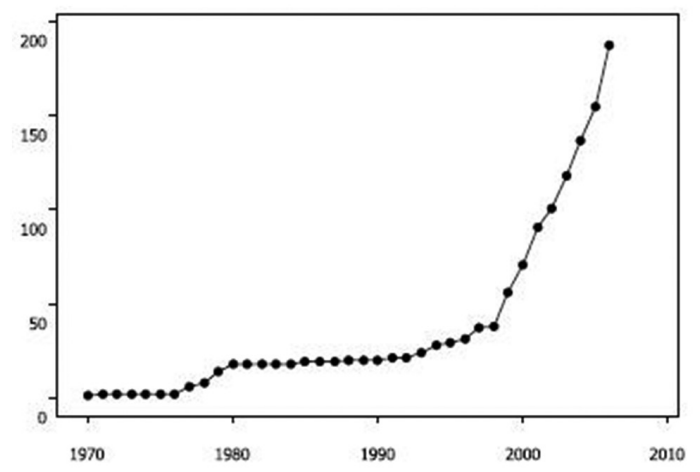

Figura 1. Crescimento dos cursos de Engenharia de Produção no Brasil. Fonte: Borchardt et al. (2009). 
Quadro 1. Áreas da Engenharia de Produção.

\begin{tabular}{|c|c|}
\hline \multicolumn{2}{|c|}{ Áreas da Engenharia de Produção } \\
\hline 1. Engenharia de operações e processos da produção & 5. Engenharia do produto \\
\hline 1.1 Gestão de Sistemas de Produção e Operações & 5.1 Gestão do Desenvolvimento de Produto \\
\hline 1.2 Planejamento, Programação e Controle da Produção & 5.2 Processo de Desenvolvimento do Produto \\
\hline 1.3 Gestão da Manutenção & 5.3 Planejamento e Projeto do Produto \\
\hline $\begin{array}{l}\text { 1.4 Projeto de Fábrica e de Instalações lndustriais: organização } \\
\text { industrial, layout/arranjo físico }\end{array}$ & 6. Engenharia organizacional \\
\hline $\begin{array}{l}\text { 1.5 Processos Produtivos Discretos e Contínuos: procedimentos, } \\
\text { métodos e sequências }\end{array}$ & 6.1 Gestão Estratégica e Organizacional \\
\hline 1.6 Engenharia de Métodos & 6.2 Gestão de Projetos \\
\hline 2. Logística & 6.3 Gestão do Desempenho Organizacional \\
\hline 2.1 Gestão da Cadeia de Suprimentos & 6.4 Gestão da Informação \\
\hline 2.2 Gestão de Estoques & 6.5 Redes de Empresas \\
\hline 2.3 Projeto e Análise de Sistemas Logísticos & 6.6 Gestão da lnovação \\
\hline 2.4 Logística Empresarial & 6.7 Gestão da Tecnologia \\
\hline 2.5 Transporte e Distribuição Física & 6.8 Gestão do Conhecimento \\
\hline 2.6 Logística Reversa & 8.3 Sistemas de Gestão de Higiene e Segurança do Trabalho \\
\hline 3. Pesquisa operacional & 8.4 Gestão de Riscos de Acidentes do Trabalho \\
\hline 3.1 Modelagem, Simulação e Otimização & 9. Engenharia da sustentabilidade \\
\hline 3.2 Programação Matemática & 9.1 Gestão Ambiental \\
\hline 3.3 Processos Decisórios & 9.2 Sistemas de Gestão Ambiental e Certificação \\
\hline 3.4 Processos Estocásticos & 9.3 Gestão de Recursos Naturais e Energéticos \\
\hline 3.5 Teoria dos Jogos & 9.4 Gestão de Efluentes e Resíduos Industriais \\
\hline 3.6 Análise de Demanda & 9.5 Produção mais Limpa e Ecoeficiência \\
\hline 3.7 Inteligência Computacional & 9.6 Responsabilidade Social \\
\hline 4. Engenharia da qualidade & 9.7 Desenvolvimento Sustentável \\
\hline 4.1 Gestão de Sistemas da Qualidade & 10. Educação em engenharia de produção \\
\hline 4.2 Planejamento e Controle da Qualidade & 10.1 Estudo da Formação do Engenheiro de Produção \\
\hline 4.3 Normalização, Auditoria e Certificação para a Qualidade & $\begin{array}{l}\text { 10.2 Estudo do Desenvolvimento e Aplicação da Pesquisa e da } \\
\text { Extensão em Engenharia de Produção }\end{array}$ \\
\hline 4.4 Organização Metrológica da Qualidade & $\begin{array}{l}\text { 10.3 Estudo da Ética e da Prática Profissional em Engenharia de } \\
\text { Produção }\end{array}$ \\
\hline 4.5 Confiabilidade de Processos e Produtos & $\begin{array}{l}\text { 10.4 Práticas Pedagógicas e Avaliação do Processo de Ensino- } \\
\text { Aprendizagem em Engenharia de Produção }\end{array}$ \\
\hline & $\begin{array}{l}10.5 \text { Gestão e Avaliação de Sistemas Educacionais de Cursos de } \\
\text { Engenharia de Produção }\end{array}$ \\
\hline
\end{tabular}

Fonte: ABEPRO (ASSOCIAÇÃO..., 2011).

correspondem aos paradigmas da administração pública vigentes em cada época: patrimonialista, burocrático e gerencial. Essa abordagem é adotada por vários outros teóricos como Marini (1996), Silva Pacheco (1999) e Pacheco (2008), principalmente por seu caráter didático e elucidativo, que contribui, sobremaneira, para o entendimento desse processo. Nessas três fases, que serão apresentadas de forma mais detalhada a seguir, as mudanças de paradigma foram acontecendo à medida que a administração pública foi evoluindo em conformidade à sociedade, de modo a tentar suprir as demandas da população pelos serviços públicos (MACROPLAN, 2005).

Quando alguns feudos da Europa começaram a conquistar e anexar territórios vizinhos, tornou-se necessário algum tipo de organização que permitisse a manutenção de tudo que havia sido conquistado (ELIAS, 1993). Começavam a se organizar, na transição da ldade Média para a ldade Moderna, por volta do século XVl, os Estados-nação (BRESSER-PEREIRA, 2006).

\subsubsection{O modelo patrimonialista}

Os Estados-nação do início da ldade Moderna se constituíam numa forma primitiva de administração, cujos esforços eram, basicamente, o de administrar e assegurar a posse dos bens existentes sob os domínios territoriais. Dessa forma, esse modelo de administração pública foi chamado de modelo patrimonialista e seus objetivos principais eram garantir a ordem do território e do patrimônio, valendo-se de meios militares.

Esses Estados, geralmente erigidos sob a égide de um governo absolutista monárquico, começaram a perder força a partir do momento em que, devido à ascensão do capitalismo e da democracia, a 
população passou a exigir uma separação entre os bens patrimoniais do Estado e dos seus governantes, os monarcas (PACHECO, 2008). Essa indissociabilidade dos bens era vista como uma forma dos governantes se apropriarem dos impostos coletados sem nenhum tipo de contrapartida à sociedade, fator que ensejou a busca por um novo modelo de administração pública.

\subsubsection{O modelo burocrático}

0 modelo burocrático surgiu como resposta a essas pressões populares como forma de proteger os bens do Estado, que se acumulavam com o passar do tempo, da gana de seus governantes. Além disso, era preciso dotar o Estado de uma estrutura capaz de combater a corrupção, o clientelismo e o fisiologismo característicos do modelo anterior (PACHECO, 2008), no qual o Estado era visto como uma extensão da riqueza dos monarcas governantes e da nobreza.

A burocracia apresentava-se neste momento histórico como um paradigma para além da administração pública. Em meados do século XIX, com o crescimento das organizações oriundas da Revolução Industrial, a burocracia era também adotada como modelo para o desenvolvimento das empresas e amplamente estudada pela nova ciência que surgia, também, nesta época: a sociologia.

Max Weber foi o principal sociólogo associado ao estudo da burocracia. Segundo Aragão (1997), Weber definiu a burocracia como uma forma superior de organização social e de dominação (racional-legal), sendo, por muitos, considerado o principal porta-voz da ideia de a burocracia ser capaz de levar as organizações a atingirem maiores graus de eficiência. 0 conceito de burocracia pode ser definido como:

Agrupamento social que rege o princípio da competência definida mediante regras, estatutos, regulamentos, da documentação, da hierarquia funcional, da especialização profissional, da permanência obrigatória do servidor na repartição durante determinado período de tempo, e da subordinação do exercício dos cargos a normas abstratas. (GUERREIRO RAMOS, 1966).

Pacheco (2008) sintetiza o conceito de burocracia numa série de características que se apresentam nesse modelo burocrático da administração pública, e que são mostrados a seguir:

- Estrutura de autoridade impessoal;

- Hierarquia de cargos baseada em um sistema de carreiras altamente especificado;

- Cargos com claras esferas de competência e atribuições;

- Sistema de livre seleção para preenchimento dos cargos, baseado em regras específicas e contrato claro;
- Seleção com base em qualificação técnica (há nomeação e não eleição);

- Remuneração expressa em moeda e baseada em quantias fixas, graduada conforme o nível hierárquico e a responsabilidade do cargo;

- 0 cargo como a única ocupação do burocrata;

- Promoção baseada em sistema de mérito (meritocracia);

- Separação entre os meios de administração e a propriedade privada do burocrata;

- Sistemática e rigorosa disciplina e controle do cargo; e

- Normatização, com controles rígidos e a priori, de processos e procedimentos.

Essas reformas burocráticas eclodiram a partir da metade do século XIX em vários contextos nacionais diferentes. As mais expressivas dessas reformas e as que mais contribuem para a popularização da burocracia mundo afora são aquelas ocorridas na Prússia, na Inglaterra, na França e nos Estados Unidos (ver BRESSER-PEREIRA, 2005)

Cabe ressaltar ainda que o modelo burocrático de Estado esteve vinculado a um acúmulo de funções gradual, que foi tornando a estrutura governamental cada vez mais pesada. Segundo Coutinho e Campos (2001), o Estado burocrático acumulou, respectivamente, os papéis de agente social, agente econômico e agente fiscal, configurando-se como o Megaestado.

Deste período se depreende que a proposta burocrática é suficiente para coibir os excessos do modelo patrimonialista, mas não tarda para que a sociedade passe a exigir um novo paradigma na administração pública. Segundo Marini (1996), a crise do modelo burocrático e, consequentemente, do Megaestado, se dá a partir do momento em que aumenta a velocidade das mudanças no recente mundo contemporâneo. 0 modelo burocrático de Estado, com sua grande quantidade de regras e com sua estrutura pesada e onerosa, não é mais suficiente para atender as demandas de um mundo globalizado e flexível. Além disso, o Megaestado acumulou déficits e não se mostrou sustentável financeiramente a longo prazo.

\subsubsection{O modelo gerencial}

0 modelo gerencial surgiu a seguir, como forma de tentar contornar os problemas do Megaestado. Aliado a essa percepção de fragilidade da administração burocrática somava-se a crença, presente em boa parte da administração pública, de que o setor privado possuía o modelo ideal de gestão. Dessa forma, foi nesse contexto de escassez de recursos públicos, enfraquecimento do poder do Estado e de avanço de 
uma ideologia privatizante, que o modelo gerencial se implantou no setor público (ABRUC10, 1997).

A eficiência, que segundo Torres (2004, p. 175) pode ser definida como

[...] fazer o melhor com menores custos, utilizando a racionalidade econômica que busca maximizar os resultados e minimizar os custos, preocupando-se com os mecanismos mais econômicos e viáveis para a obtenção do êxito da ação estatal [...].

na verdade, nunca foi atingida através do modelo burocrático que, como já foi dito, acabou por gerar grande ineficiência apesar do combate eficaz aos excessos do modelo patrimonialista. No entanto, apesar da emergência da eficiência, é a eficácia que é a grande força motriz desse modelo de gestão.

Segundo Castro (2006), eficácia está relacionada ao atingimento dos objetivos desejados por determinada ação estatal, em oposição à eficiência que, como já dito, se preocupa com os mecanismos e a viabilidade econômica dessas ações. E é em busca dessa eficácia que a reforma que implantou o modelo gerencial na administração pública brasileira definiu, segundo Silva Pacheco (1999), quatro eixos básicos de atuação e, sobre cada uma delas, será dada uma breve explanação, quais sejam: 1) delimitação da área de atuação do Estado; 2) desregulamentação; 3) governança: aumento da capacidade de governo; e 4) governabilidade: aumento da democracia e da accountability.

Quanto à delimitação da área de atuação do Estado, o que ocorreu, segundo Silva Pacheco (1999), foi a distinção das atividades exclusivas do Estado (núcleo estratégico, compreendendo as secretarias formuladoras de políticas, as agências executivas e as agências reguladoras) daquelas em que não há exercício de poder de Estado, mas que envolvem direitos humanos fundamentais ou geram externalidades que não devem ser apropriadas privadamente (serviços sociais e científicos).

0 segundo eixo foi a desregulamentação. Segundo Silva Pacheco (1999) a proposta foi a de reduzir a regulamentação aos aspectos em que ela é absolutamente necessária. Ainda segundo Silva Pacheco (1999), na transição para o modelo gerencial, uma série de medidas deve contribuir para a diminuição do chamado "entulho burocrático" - disposições normativas excessivamente detalhadas, que só contribuem para o engessamento da máquina e muitas vezes para sua intransparência.

Quanto à governança, que pode ser entendida como o aumento da capacidade de governo, o que houve foi a adoção dos princípios da administração gerencial, sintetizados por Bresser-Pereira (1997) nos seguintes elementos: 1) orientação da ação do Estado para o cidadão-usuário de seus serviços; 2) ênfase no controle de resultados através dos contratos de gestão; 3) fortalecimento e autonomia da burocracia nas competências essenciais das atividades típicas de Estado, em seu papel político e técnico de participar, junto com os políticos e a sociedade, da formulação e gestão de políticas públicas; 4) separação entre as secretarias formuladoras de políticas e suas unidades executoras e contratualização da relação entre elas, baseada no desempenho de resultados; 5) adoção cumulativa de três formas de controle sobre as unidades executoras de políticas públicas: controle social direto (através da transparência das informações e da participação em conselhos); controle hierárquicogerencial sobre resultados (através do contrato de gestão); e 6) controle pela competição administrada, via formação de quase mercados. Cabe ressaltar que este terceiro eixo, em especial, será o grande pilar do movimento da Nova Gestão Pública.

0 último dos eixos do modelo gerencial é a governabilidade. Bresser-Pereira (1997) afirma que a governabilidade depende de várias dimensões políticas, dentre elas a qualidade das instituições políticas quanto à intermediação de interesses e a existência de mecanismos de responsabilização (accountability) dos políticos e burocratas perante a sociedade.

\subsection{A Nova Gestão Pública}

A Nova Gestão Pública pode ser compreendida, na verdade, como um refinamento do modelo gerencial. Em termos da forma de administração, não apresenta uma grande ruptura em relação ao modelo gerencial. A Nova Gestão Pública deve, portanto, ser entendida, como um movimento evolucionário, em vez de revolucionário.

Pollitt (1990) afirma que o movimento da nova administração pública pode ser visto como um sistema de pensamento caracterizado pela importação de ideias geradas em áreas do setor privado para dentro das organizações do setor público, posicionamento também adotado por outros autores, como Ferlie et al. (1999).

Pacheco $(2008$, p. 27) nos apresenta uma definição bastante compreensiva e abrangente do que se define como Nova Gestão Pública:

[...] um modelo emergente de modernização da administração pública mundial, caracterizado por um conjunto de princípios e práticas de gestão, oriundos de um movimento de governos de diversos países no sentido de desenvolver alternativas e soluções para os desafios aos quais eram e ainda são colocados (como escassez de recursos públicos, aumento da pressão da sociedade por qualidade e equidade na prestação de serviços etc.), e para os quais o modelo burocrático não se mostrou capaz de responder satisfatoriamente. 
A Nova Gestão Pública emerge como resposta às crescentes demandas da sociedade por serviços públicos de melhor qualidade e por mudanças efetivas na realidade social, econômica e ambiental, tudo isso em um ambiente marcado pelo fortalecimento da cidadania, pela expansão das funções econômicas e sociais do Estado, pelo desenvolvimento tecnológico e pela globalização da economia mundial (MACROPLAN, 2005).

Segundo Matias Pereira (2007), a Nova Gestão Pública (NGP) é um movimento que começa a tomar corpo na década de 1980 e ganha força mundo afora na década de 1990. Ataide (2005) aponta, particularmente, quatro exemplos emblemáticos de ações associadas a esse movimento nos seguintes países: Estados Unidos, Reino Unido, Nova Zelândia e Austrália, que podem ser vistos na Tabela 1.

Marini e Martins (2002) sintetizam sua visão a respeito da Nova Gestão Pública em cinco princípios, sejam eles: 1) o foco no cidadão/cliente; 2) orientação para resultados; 3) ênfases no controle social e transparência; 4) contratualização e flexibilização da gestão; e 5) valorização e desenvolvimento das pessoas. Segundo os autores, algumas ferramentas são sugeridas para cada um dos elementos levantados, de forma que para a "orientação para resultados" é sugerida a utilização de indicadores de desempenho e de planejamento estratégico, que já são ferramentas bem conhecidas no universo de trabalho do engenheiro de produção.

Pacheco (2008) utiliza uma definição de princípios bastante próxima àquela apresentada por Marini e Martins (2002). Segundo Pacheco (2008), os princípios norteadores da Nova Gestão Pública são: 1) governança democrática; 2) orientação para resultados; 3) atitude e ambiente empreendedores; 4) descentralização de serviços; 5) valorização da gestão de pessoas; 6) articulação de recursos públicos e privados; e 7) responsabilização e contratualização, cujas definições podem ser encontradas na Tabela 2. Para o propósito deste trabalho, optamos por utilizar a abordagem de Pacheco (2008) que, por sua vez, é oriunda da abordagem de Marini e Martins (2002).

É importante ressaltar neste trabalho que o modelo da Nova Gestão Pública tem sofrido críticas do ponto de vista técnico-gerencial. Segundo Dunleavy et al. (2005), o movimento da Nova Gestão Pública vai aos poucos sendo substituído pelo movimento da governança digital, no qual as técnicas e ferramentas associadas à gestão da informação apresentam-se como um elemento mais relevante para a elaboração das políticas públicas do que aquelas associadas

Tabela 1. Implementação da Nova Gestão Pública.

\begin{tabular}{ll}
\hline \multicolumn{1}{c}{ Paises } & \multicolumn{1}{c}{ Processo de implementação } \\
\hline Reino Unido & $\begin{array}{l}\text { Pioneiro no processo de reforma do Estado, décadas de 1980-1990. Preocupação primeiro com a redução de gastos e da } \\
\text { estrutura estatal (privatizações etc.). } \\
\text { Implantação de novo modelo de gestão das finanças públicas, com o objetivo de melhorar a situação fiscal do país a } \\
\text { médio e longo prazo. } \\
\text { Nova Zelândia }\end{array} \quad \begin{array}{l}\text { Receituário clássico de enxugamento de um Estado oneroso. lnstituíram-se mecanismos de avaliação pública que serviam } \\
\text { de base para as decisões de alocação orçamentária. } \\
\text { Institui o GPRA (Government Performance and Results Act) em 1993, legislação orientada para a execução e aferição } \\
\text { de resultados de programas governamentais, integração entre plano e orçamento e ênfase no aprimoramento das } \\
\text { informações de natureza gerencial para aprimorar os processos de planejamento. }\end{array}$ \\
\hline Fonte: Ataide (2005). &
\end{tabular}

Tabela 2. Princípios da Nova Gestão Pública.

\begin{tabular}{|c|c|}
\hline Princípio & Definição \\
\hline Governança democrática & $\begin{array}{l}\text { Focalização da ação do Estado no cidadão; resgate da esfera pública como instrumento do exercício da } \\
\text { cidadania; prestação de contas com relação às políticas e resultados propostos; transparência nas ações. }\end{array}$ \\
\hline Orientação para resultados & $\begin{array}{l}\text { Controles baseados em indicadores de resultados; identificação do público-alvo das ações de governo; } \\
\text { resultados de impactos (outcomes) em detrmimento dos resultados de serviços (outputs). }\end{array}$ \\
\hline $\begin{array}{l}\text { Atitude e ambiente } \\
\text { empreendedores }\end{array}$ & $\begin{array}{l}\text { Estímulo à criatividade e inovação por parte das organizações públicas e, principalmente, dos servidores } \\
\text { públicos. }\end{array}$ \\
\hline Descentralização de serviços & $\begin{array}{l}\text { Estado com ênfase na regulação e na promoção do atendimento às demandas sociais, desempenhando a } \\
\text { função de articulador. }\end{array}$ \\
\hline Valorização da gestão de pessoas & $\begin{array}{l}\text { Resgate da imagem do servidor público; estabelecimento de relações profissionais de trabalho; alcance dos } \\
\text { resultados organizacionais; criação de condições objetivas de desenvolvimento das pessoas. }\end{array}$ \\
\hline $\begin{array}{l}\text { Articulação de recursos públicos } \\
\text { e privados }\end{array}$ & $\begin{array}{l}0 \text { governo delega ao setor privado aspectos tipicamente mercantis do empreendimento, mantendo suas } \\
\text { prerrogativas de planejamento, monitoramento e regulamentação. Exemplos: parcerias público-privadas } \\
\text { (PPPs); Project Finance. }\end{array}$ \\
\hline $\begin{array}{l}\text { Responsabilização e } \\
\text { contratualização }\end{array}$ & $\begin{array}{l}\text { Responsabilização das organizações prestadoras de serviços, sejam elas públicas ou não; monitoramento e } \\
\text { avaliação é prerrogativa do Estado; criação de mecanismos de controle; garantia do alcance dos resultados } \\
\text { esperados. }\end{array}$ \\
\hline
\end{tabular}


à estrutura organizacional. Tal argumentação é reforçada por Margetts (2009), que aponta que a descentralização de serviços, prevista no modelo da Nova Gestão Pública, contrasta diretamente com a reintegração dos dados e operações preconizadas pelo modelo da governança digital. Osborne (2010), no entanto, identifica como tendência futura uma nova perspectiva intitulada de nova governança pública, que mescla aspectos da Nova Gestão Pública e da governança digital.

Ainda que haja essas críticas ao modelo da Nova Gestão Pública, vale ressaltar que a discussão proposta por este artigo é válida, especialmente porque, no Brasil, o processo de transição paradigmática em direção a novos modelos de gestão pública tem se dado em um grau mais lento do que o dos países que efetuaram mais cedo suas reformas gerenciais (Reino Unido, Estados Unidos, Austrália), o que faz com que os pressupostos básicos da Nova Gestão Pública sejam válidos para compreendermos a forma de atuação dos engenheiros de produção no setor público.

\section{Metodologia}

0 presente estudo realiza uma investigação das práticas de gestão associadas à Engenharia de Produção que são possíveis de ocorrer na administração pública, segundo cada um dos paradigmas da Nova Gestão Pública.

Essa investigação é realizada de modo mais teórico do que empírico, na busca de associações lógicas entre as áreas da Engenharia de Produção e os paradigmas da Nova Gestão Pública. Ainda assim, alguns exemplos foram extraídos da literatura disponível, no sentido de elucidar algumas das práticas apresentadas.

Ao final, apresenta-se um quadro-resumo, no qual podem ser observados quais são os relacionamentos percebidos entre cada um dos elementos (áreas ou paradigmas) apresentados.

\section{Discussão e resultados}

No paradigma da governança democrática, o governo deve centrar seus esforços no que é bom para o cidadão, mantendo-se em constante diálogo sobre as suas necessidades e as de seu entorno. De acordo com Castro (2006), essa governança democrática deve ser a mais transparente e responsável possível, buscando sintonizar e sensibilizar a população para a implementação das políticas públicas Nesse sentido, práticas de gestão relacionadas à sustentabilidade emergem como uma forma de garantir que sejam atendidos os interesses não apenas dos cidadãos, mas daqueles que não podem se fazer representar, dentre os quais incluem-se a fauna, a flora e a biosfera. Registre-se também que, nesse processo de governança democrática, os interesses dos ricos e dos pobres devem ser ouvidos de forma indistinta na construção de um projeto de governo. Dessa forma, abordagens e ferramentas relacionadas à sustentabilidade social e ambiental podem ser utilizadas por engenheiros de produção que trabalham sob esse paradigma. Uma dessas ferramentas é o triple bottom-line (OLIVEIRA et al., 2012), que é uma esquematização triangular que engloba os aspectos econômicos, sociais e ambientais de um sistema, conforme consta na Figura 2. Dentro do mesmo paradigma, no sentido de garantir a transparência governamental, podem ser utilizadas ferramentas da área da engenharia de qualidade, como a definição de um sistema de qualidade e de um controle através de auditorias, tanto internas quanto externas.

A orientação para resultados é, sem dúvida, o paradigma da Nova Gestão Pública que mais apresenta possiblidades de intervenção do engenheiro de produção no Estado. Este é o paradigma que mais aproxima as organizações públicas das organizações privadas, na medida em que toda orientação privada funciona orientada para resultados, sejam eles financeiros ou não. Em um plano mais macro, esse aspecto está bastante relacionado à engenharia organizacional. Portanto, técnicas e ferramentas como gestão de projetos, utilização de indicadores de desempenho (FRYER; ANTONY; OGDEN, 2009) e planejamento estratégico podem ser utilizados na Nova Gestão Pública.

Quanto ao planejamento estratégico, Matias Pereira (2007) afirma que é função explícita do Estado o ato de planejar. A Constituição Federal do Brasil (BRASIL, 1988), em seu artigo 174, coloca o planejamento governamental como uma imposição legal, afirmando que, por se tratar de agente normativo e regulador da atividade econômica, é o Estado quem deve arcar com as funções de fiscalização, incentivo e planejamento, sendo estas de forma determinante para o setor público e de forma indicativa para o setor privado.

Quanto aos elementos do plano estratégico, Coutinho e Campos (2001) defendem a ideia de que o Estado deve possuir missão, visão, indicadores e metas, tal qual uma empresa privada. No entanto, Pfeiffer (2000) aponta para as diferenças existentes

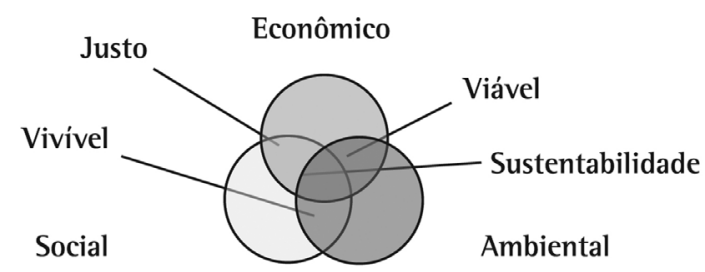

Figura 2. Triple Bottom line. Fonte: Oliveira et al. (2012). 
entre o setor público e o setor privado na construção desse planejamento. Pfeiffer (2000) afirma, contudo, que, independentemente das idiossincrasias de cada situação na escolha do formato do plano, as funções básicas do planejamento estratégico são as mesmas: facilitar e melhorar a comunicação entre os membros da organização e os seus parceiros; facilitar e estimular a participação dos stakeholders; conciliar os diversos interesses internos e/ou externos e garantir a implementação de medidas. Jesus e Pacheco (2009) apresentam um estudo recente sobre a utilização da ferramenta planejamento estratégico no setor público, especificamente, no governo do Estado do Rio de Janeiro.

Ainda sobre a orientação para resultados, pode-se dizer que esse paradigma se relaciona também com aspectos da engenharia da qualidade, em especial à abordagem dos prêmios de qualidade, através do qual uma organização, seja ela pública ou não, pode mensurar o seu desempenho em relação ao grau de excelência da sua gestão. Nestes prêmios, como por exemplo, o PNQ, que pode ser visto na Figura 3, a orientação para resultados aparece como prerrogativa básica do sistema. Em um plano mais detalhado, as ferramentas e técnicas de planejamento estratégico e de prêmios de qualidade podem ser desdobradas em alguns aspectos mais específicos da Engenharia de Produção como: técnicas de controle e gerenciamento da produção para tarefas mais rotineiras, como a coleta de lixo, por exemplo; a previsão de demanda para os produtos/serviços oferecidos pelo Estado; a contabilidade e a gestão de custos, e a gestão dos investimentos. Em alguns problemas mais complexos, podem ser utilizadas técnicas de pesquisa operacional para otimizar o uso dos recursos na busca dos

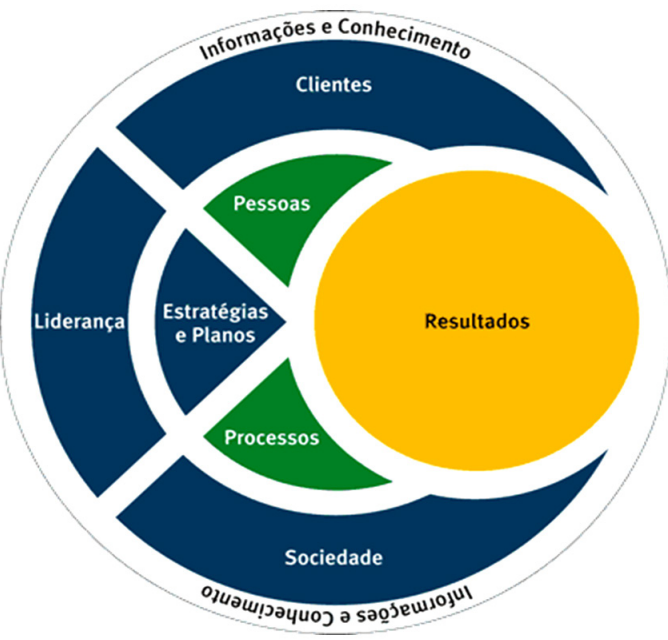

Figura 3. Modelo de excelência do PNQ. Fonte: PNQ (PRÊM1O..., 2007). resultados pretendidos ou para a elaboração de metas para esses resultados. Dentre essas técnicas, podem ser citadas simulações, programação linear, abordagem multicritério (COSTA, 2006) e análise envoltória de dados (ANGULO-MEZA; SOARES DE MELLO; ClíMACO, 2006). Ainda no paradigma da orientação para resultados, ressalte-se a concepção e o projeto do produto. No qua tange a escolas, hospitais e outros equipamentos que sejam vetores das políticas públicas, apenas aqueles que sejam projetados levando-se em conta as suas funcionalidades e as necessidades de seu público-alvo serão capazes de gerar os resultados esperados pelo Estado.

Quanto à criação e manutenção de atitude e ambiente empreendedores no Estado, a principal interesecção se dá na educação em Engenharia de Produção. Tais características são paulatinamente desenvolvidas no engenheiro de produção durante a sua formação e é importante que essas características sejam repassadas àqueles que forem trabalhar no Estado. Esse compartilhamento do conhecimento pode se dar tanto através de capacitações dos professores de Engenharia de Produção aos funcionários do Estado no intuito de desenvolver as características empreendedoras quanto no sentido de desenvolver competências no engenheiro de produção durante a sua formação para que os mesmos se tornem aptos a servir como elemento difusor do empreendedorismo nos órgãos públicos em que vierem a trabalhar. $A$ criação de tal ambiente empreendedor também envolve o projeto de um ambiente de trabalho, bem como de ferramentas de gestão da inovação, que favoreçam o desenvolvimento da criatividade e da inovação no setor público.

No que diz respeito à descentralização de serviços, pode-se depreender facilmente que os aspectos relacionados à logística são aqueles que adquirem maior importância. Os esforços logísticos de controle dos estoques e da cadeia de suprimentos, bem como aqueles ralativos ao planejamento dos transportes tornam-se muito mais complexos à medida que uma estrutura descentralizada precisa ser gerida. Além disso, é possível compreender cada uma das unidades descentralizadas de qualquer serviço prestado pelo Estado como unidades de negócio, ou, ainda, como unidades de produção. Dessa forma, aplicam-se a essas unidades técnicas de planejamento e controle da produção. Podem também ser úteis ferramentas de gestão dos sistemas de produção, no sentido de que a máquina governamental pode ser entendida como um ente produtivo único, apesar de possuir descentralização de atividades. Para garantir que essa descentralização possa existir de forma coesa, além dos esforços logísticos e operacionais, é necessário que o próprio trabalhado seja constantemente repensado, tanto em seu projeto quanto na forma em que se organiza, de forma a garantir que haja coordenação, 
entrosamento e conexões entre as atividades a serem realizadas nas unidades descentralizadas. Essas unidades descentralizadas, na maior parte das vezes, pode ser encarada como uma rede, cujo funcionamento acontece de forma sistêmica e articulada com as outras unidades.

Para atingir o paradigma da valorização da gestão de pessoas, o primeiro passo é encarar as pessoas como um dos ativos mais importantes da organização. Dessa forma, programas e atividades que realizem a gestão do conhecimento na organização, que mantenham a ergonomia e a segurança do trabalho de seus funcionários, que possuam mecanismos econômicos e financeiros de valorização do servidor público e que estabeleçam metas de desempenho para que as progressões e promoções ocorram de forma majoritariamente meritocrática dão respaldo à manutenção do engenheiro de produção no Estado, como elemento indutor dessas mudanças e como gestor e mantenedor dessas conquistas. Além disso, a valorização da gestão de pessoas se dá também através de cursos e capacitações, inclusive em áreas afins à Engenharia de Produção, incluindo-se a própria, para que essa visão de valorização das pessoas no serviço público possa se perpetuar.

Contrapondo-se simultaneamente ao Megaestado, da administração burocrática, e ao Estado Mínimo, da reforma gerencial, a utilização de recursos públicos e privados no Estado, de forma articulada, é um dos paradigmas que se configura como um elemento bastante representativo da Nova Gestão Pública em relação aos modelos anteriormente vigentes. Representada na prática cotidiana basicamente pelas parcerias público-privadas (PPPs), as boas práticas associadas a essas parcerias estão associadas, principalmente, a técnicas e ferramentas de gestão de projetos e também à gestão de investimentos e de investimentos. Podem ser citados como exemplos a utilização de metodologias de gerenciamento de projetos como escritório de projetos (MARTINS et al., 2005). Rego e Silva (2011) apresentam os desafios de implantação de um escritório de projetos em governos estaduais, como o caso do EGP-RIO (Escritório de Gerenciamento de Projetos do Estado do Rio de Janeiro). Dentro do mesmo paradigma, citam-se como práticas também a utilização de project finance e a utilização de ferramentas de viabilidade econômica de projetos, tais como valor presente líquido (VPL), taxa interna de retorno (TIR), etc. (GATTI, 2012).

No que tange à responsabilização e contratualização de resultados, podem ser utilizadas, sobretudo, ferramentas que trabalhem com o monitoramento do desempenho organizacional e com a gestão da informação. É necessário deixar bem claro quais são os deveres e obrigações pactuados por cada uma das partes, cujo controle se dá tanto de maneira formal, pelos indicadores de gestão estabelecidos, conforme visto na discussão sobre o paradigma da orientação para resultados, quanto através das ferramentas de controle popular, conforme vistas na discussão sobre a governança democrática. Trosa (2001) alerta para a importância de se prestar atenção a quais resultados a organização pública busca. Para tanto, é necessário que se busque e que se defina de forma clara, num primeiro momento, o seu público-alvo, isto é, o grupo de pessoas ou instituições que são beneficiários diretos dos resultados propostos. Pacheco (2008) acrescenta ainda a importância de a administração pública trabalhar com resultados finalísticos (ou de outcomes), ou seja, aqueles resultados que permitem medir e avaliar as transformações ou impactos gerados em seu público-alvo (por exemplo, redução do número de homicídios por 100 mil habitantes, aumento da taxa de sobrevivência das micro e pequenas empresas brasileiras etc). A partir do momento em que o foco da atuação pública se volta para os usuários/cidadãos, a medição de resultados de output (quilômetros de estradas construídos, cursos realizados, cidadãos atendidos etc.), que não medem o impacto de cada um desses dados na vida do cidadão, torna-se inadequada e insuficiente frente a princípios como transparência, prestação de contas e controle social por parte da sociedade. Ainda quanto à parte da contratualização dos resultados, é importante que haja uma política de informação que estabeleça critérios para quais partes da contratualização podem ser vistas por quais entidades. 0 objetivo dessa política de informação deverá ser o de tornar essa contratualização e responsabilização as mais transparentes possíveis, evitando onerar o cidadão com informações desnecessárias e garantindo que as informações corretas sobre os contratos e seus resultados cheguem de forma eficaz àqueles que as demandam (DELAIA; FREIRE, 2010).

A Tabela 3 apresenta um resumo dessa discussão, estabelecendo as correlaçõe existentes entre cada um dos paradigmas da Nova Gestão Pública e as áreas da Engenharia de Produção que a eles estejam associadas.

Ao observarmos a Tabela 3, podemos perceber que todos os paradigmas da Nova Gestão Pública podem ser colocados em prática através da utilização de engenheiros de produção no Estado e que todas as subáreas da Engenharia de Produção servem ao Estado, no intuito de serem úteis à execução de pelo menos um dos paradigmas da Nova Gestão Pública.

Pode-se perceber também que a maior oportunidade para atuação do engenheiro de produção no setor público governamental é na subárea da engenharia organizacional, seguida por engenharia econômica, engenharia da qualidade e engenharia do trabalho. Percebe-se também que, dentre os paradigmas da Nova Gestão Pública apresentados, aqueles que mais se beneficiariam do trabalho do 
Tabela 3. Interfaces entre Engenharia de Produção e Nova Gestão Pública.

\begin{tabular}{|l|c|c|c|c|c|c|c|}
\cline { 2 - 7 } & & & & & & \\
\end{tabular}

Fonte: elaborada pelos autores.

engenheiro de produção seriam a orientação para resultados e a valorização da gestão de pessoas.

\section{Conclusão}

Pode-se concluir com este estudo que as interfaces existentes entre a Engenharia de Produção e a Nova Gestão Pública são múltiplas e ocorrem de forma a abarcar todas as subáreas da Engenharia de Produção e todos os paradigmas da Nova Gestão Pública.

Depreende-se, portanto, que a contratação de engenheiros de produção é vantajosa para o Estado, pois permite que os mesmos sejam aproveitados no sentido de reforçar todos os paradigmas da Nova Gestão Pública, contribuindo para um Estado cada vez mais moderno e mais democrático.

Por outro lado, pode-se perceber que o leque de opções de trabalho para o engenheiro de produção no setor público é tão amplo quanto na iniciativa privada. Em um Estado onde são vigentes ou estão em construção os paradigmas da Nova Gestão Pública, como é o caso do Estado brasileiro, o engenheiro de produção pode trabalhar para o setor público e, dentro de quaisquer de suas esferas de competências, ou de suas subáreas de atuação, contribuir para a melhoria do setor público no Brasil.

\section{Referências}

ASSOCIAÇÃO BRASILEIRA, DE ENGENHARIA DE PRODUÇÃO - ABEPRO. Áreas e subáreas de Engenharia de Produção. Disponível em: <http://www.abepro.org. br>. Acesso em: 10 jan. 2011.

ABRUC10, F. L. O impacto do modelo gerencial na administração púbica: um breve estudo sobre a experiência internacional recente. Brasília: Enap, 1997. (Cadernos ENAP, n. 10).
ANGULO-MEZA, L.; SOARES DE MELLO, J. C. C. B.; CLÍMACO, J. C. N. Estudos conjuntos de análise envoltória de dados (DEA) e programação linear multiobjetivo (PLMO): uma revisão bibliográfica. Relatórios de Pesquisa em Engenharia de Produção (UFF), v. 6, p. 5, 2006.

ARAGÃO, C. V. Burocracia, eficiência e modelos de gestão pública: um ensaio. Revista do Serviço Público, v. 48, n. 3, set./dez. 1997.

ATAIDE, P. A. B. Avaliação de resultados: a experiência do Governo Federal. In: LEVY, E.; DRAGO, P. A. (Org.). Gestão pública no Brasil contemporâneo. São Paulo: Fundap, 2005.

BORCHARDT, M. et al. 0 perfil do engenheiro de produção: a visão de empresas da região metropolitana de Porto Alegre. Produção, v. 19, n. 2, maio/ago. 2009. http:// dx.doi.org/10.1590/S0103-65132009000200002

BRASIL. Constituição (1988). Constituição da República Federativa do Brasil. Brasília: Senado Federal, 1988.

BRESSER-PEREIRA, L. C. Construção do Estado e Administração Pública: uma abordagem histórica. São Paulo: FGV, 2005. Relatório de Pesquisa FGV-EAESP n. 27.

BRESSER-PEREIRA, L. C. Estratégia nacional e desenvolvimento. Revista de Economia Política, v. 26, n. 2, abr./jun. 2006. http://dx.doi.org/10.1590/S010131572006000200003

BRESSER-PEREIRA, L. C. A Reforma do Estado nos Anos 90: Lógica e Mecanismos de Controle. Brasília: MARE, 1997.

CASTRO, R. B. Eficácia, eficiência e efetividade na gestão pública. In: ENCONTRO DA ASSOCIAÇÃO NACIONAL DE PÓS-GRADUAÇÃO E PESQUISA EM ADMINISTRAÇÃO, 30., 2006, Salvador. Anais... Salvador: ANPAD, 2006.

COSTA, H. G. Auxílio multricritério à decisão: Método AHP. Rio de Janeiro: Abepro, 2006.

COUTINHO, V.; CAMPOS, M. T. O. S. Brasil Século XXI: a construção de um Estado eficaz. Brasília: ENAP, 2001. (Texto para discussão, n. 07).

DELAIA, C. R.; FREIRE, I. M. Subsídios para uma política de gestão da informação da Embrapa Solos: à luz do regime de informação. Perspectivas em Ciência da Informação, v. 15, n. 3, p. 107-130, 2010. 
DUNLEAVY, P. et al. New Public Management is dead - long live Digital Era Governance. Journal of Public Administration Research and Theory Advance Access, n. 16, p. 467-494, 2005.

ELIAS, N. O Processo Civilizatório: Vol. 11 - Formação do Estado e Civilização. Jorge Zahar Editor, 1993.

FERLIE, E. et al. A nova administração pública em ação. Brasília: EdUnB, ENAP, 1999.

FLEURY, A. 0 que é Engenharia de Produção?. In: BATALHA, M. 0. (Org.). Introdução à Engenharia de Produção. Rio de Janeiro: Elsevier, 2008.

FRYER, K.; ANTONY, J.; OGDEN, S. Performance management in public sector. International Journal of Public Sector Management, v. 22, n. 6, 2009. http://dx.doi. org/10.1108/09513550910982850

GATTl, S. Project Finance in Theory and Practice. San Diego: Elsevier, 2012.

GUERREIRO RAMOS, A. Administração e Estratégia do Desenvolvimento. Rio de Janeiro: Fundação Getúlio Vargas, 1966.

JESUS, I. R. D.; PACHECO, S. 0. Planejamento estratégico governamental: o caso do Governo do Estado do Rio de Janeiro. In: CONGRESSO INTERNACIONAL DE ADMINISTRAÇÃO, 2009, Ponta Grossa. Anais... Ponta Grossa, 2009.

MACROPLAN. A nova gestão pública: fundamentos e perspectivas. São Paulo: 2005.

MARGETTS, H. Public management change and e-government: the emergence of digital-era governance. In: CHADWICK, A.; HOPWARD, P. N. (Orgs.). Routledge handbook of Internet politics. Abingdon: Routledge, 2009.

MARINI, C. Crise e reforma do Estado: uma questão de cidadania e valorização do servidor. Revista do Serviço Público, v. 47, n. 3, set./dez. 1996.

MARINI, C.; MARTINS, H. Melhorando a Gestão Pública. Brasília: Ministério do Planejamento, Orçamento e Gestão, Programa de Apoio à Modernização da Gestão e dos Planejamento dos Estados e do Distrito Federal - PNAGE, 2002.

MARTINS, A. P. et al. Implantação e consolidação de escritório de gerenciamento de projetos: um estudo de caso. Produção, v. 15, n. 3, 2005. http://dx.doi.org/10.1590/ S0103-65132005000300010

MATIAS PEREIRA, J. Manual de Gestão Pública Contemporânea. São Paulo: Atlas, 2007.
OLIVEIRA, V.; BARBOSA, C.; CHRISPIM, E. Cursos de Engenharia de Produção: crescimento e projeções. In: ENCONTRO NACIONAL DE ENGENHARIA DE PRODUÇÃO, 25., 2005, Porto Alegre. Anais... Porto Alegre: ABEPRO, 2005.

OLIVEIRA, L. R. et al. Sustentabilidade: da evolução dos conceitos à implementação como estratégia nas organizações. Produção, v. 22, n. 1, p. 70-82, 2012. http://dx.doi.org/10.1590/S0103-65132011005000062

OSBORNE, S. P. The New Public Governance? Abingdon: Routledge, 2010.

PACHECO, S. 0. Planejamento estratégico na gestão pública: o caso do Governo do Estado do Rio de Janeiro. 2008. Monografia (Conclusão de curso)-Universidade Federal de Juiz de Fora, Juiz de Fora, 2008.

PFEIFFER, P. Planejamento estratégico municipal no Brasil: uma nova abordagem. Brasília: ENAP, 2000. (Texto para discussão, n. 37).

POLLITT, C. The new managerialism and the public services: the angloamerican experience. Oxford: Basil Blackwell, 1990.

PRÊMIO NACIONAL DA QUALIDADE - PNQ. Modelo de Excelência. Disponível em: <www.pnq.org.br>. Acesso em: 05 out. 2007.

REGO, M. L.; SILVA, T. R. Desafios na implantação de um escritório de gerenciamento de projetos em um Governo Estadual. Revista Economia \& Gestão, v. 11, n. 27, 2011. http://dx.doi.org/10.5752/P.1984-6606.2011v11n27p153

SILVA PACHECO, R. Administração pública gerencial: desafios e oportunidades para os municípios brasileiros. In: CENTRO DE ESTUDOS E PESQUISAS DE ADMINISTRAÇÃO MUNICIPAL - CEPAM (Ed.). O município no século XXI - CEPAM 30 anos. São Paulo: CEPAM, 1999. p. 39-49. http://dx.doi.org/10.5752/P.1984-6606.2011v11n27p153

TORRES, M. D. F. Estado, democracia e administração pública no Brasil. Rio de Janeiro: Editora FGV, 2004.

TROSA, S. Gestão pública por resultados: quando o estado se compromete. Brasília: Revan, ENAP, 2001.

\section{Agradecimentos}

Os autores agradecem à Capes e ao CNPq o apoio financeiro. Os autores também agradecem aos avaliadores e à editoria do periódico as contribuições ao texto.

\section{New Public Management as an inducer of Production Engineering activities in government agencies}

\section{Abstract}

The purpose of this paper is to show how New Public Management, by incorporating tools and views from the private sector, makes room for a larger role for production engineers in the government. The lntroduction presents the historical context of public management evaluation since the emergence of patrimonialist model, through the bureaucratic and managerialism models, to the rise of New Public Management. The historical context of the development of Production Engineering is also presented. The search for interfaces between these two fields of knowledge arises from a theoretical investigation in which we try to understand which management practices were associated, simultaneously, with elements of Production Engineering and New Public Management. The results of this investigation reveal that this interface affects all elements of New Public Management and all sub-areas of Production Engineering.

\section{Keywords}

New Public Management. Production engineering. Managerial reform. Public sector. Government. 